\title{
Identification of Plant Response to the Human Behavior of Crushing Plants
}

\author{
Kwang Jin Kim*, Hyeon Ju Kim, Deokjoo Son, Na Ra Jeong, Hyung Gewon Yun, Seung Won Han, Soojin You, Chan-joong Kim, \\ and Seon Hwa Lee \\ Urban Agriculture Research Division, National Institute of Horticultural \& Herbal Science, Rural Development Administration, \\ Wanju-gun 55365, Korea
}

\section{ABSTRACT}

We identified how plants affected by the human behavior of crushing plants respond and what kind of plants responded sensitively. We investigated Lactuca sativa "Gaesebadak", Syneilesis palmata and Peucedanum japonicum as plants that humans use for edible purposes, and Achyranthes japonica and Bidens bipinnata as wild plants that stick to people's clothes and disperse seed. Plants exposed to human breathing air were compared with those exposed to human breathing air after being crushed. Methyl jasmonate (MeJA), a chemical word, was measured using Syft/MS, which detects real-time VOC, and related genes were analyzed. The amount of MeJA of Syneilesis palmata and Peucedanum japonicum as edible plants was greater than that of non-edible plants that disperse seeds using humans. The amount of MeJA ranged from $0.20 \mathrm{ppb}$ to $0.35 \mathrm{ppb}$ when the control group were not exposed to human breathing air. On the other hand, MeJA decreased after increasing for the first hour in human breathing air. Also, MeJA affected by human breathing after crushing plants was higher than that affected by just human breathing air. Peucedanum japonicum showed the most distinctive difference between the treatment with human breathing after crushing plants and the treatment with just human breathing. In addition, the gene activity of JAR1 and JMT increased 3 hours after the treatment with human breathing after crushing plants. Therefore, in the treatment with human breathing after crushing plants, the concentration of MeJA and the activity of related genes showed the same tendency to increase. As a result, the plant that responded sensitively to human behavior was Peucedanum japonicum. Plants released MeJA as a chemical word in the treatment with human breathing air after crushing plants.

Keywords: chemical word, human breathing, JAR1, JMT, Methyl jasmonate

\section{Introduction}

Plants emit volatile organic compounds (VOCs) to defend themselves or attract natural enemies when damaged by insects or herbivores (Arimura et al., 2010; Heil and Karban, 2010; Holopainen and Gershenzon, 2010; Kaplan, 2012; von Mérey et al., 2011). Moreover, plants damaged by insects let other leaves or plants around them to produce defensive secretion (Arimura et al., 2010; Heil and Karban, 2010). VOC used as a substance to signal other plants around them is referred to as 'chemical word'. VOCs generated by organisms are also referred to as biogenic volatile organic compounds (BVOCs) to distinguish them from environmental pollutants (Loreto and Schnitzler, 2010). Some BVOCs are used as 'chemical word' for plant-plant or plant-insect communication (Arimura et al., 2010; Engelberth et al., 2014; Heil and Karban, 2010; Zuo et al., 2012).

When liquid jasmonate is used as the chemical word takes a long time to deliver. Thus, methyl jasmonate (MeJA) with methyl is known to be used for vaporization (Arimura

This study was supported by the research project of the Rural Development Administration (PJ01262403).

Received: November 27, 2019, Revised: December 5, 2019, Accepted: December 15, 2019

First author: Kwang Jin Kim, kwangjin@korea.kr, (1) https://orcid.org/0000-0002-2549-9720

*Corresponding author: Kwang Jin Kim, kwangjin@korea.kr, (B) https://orcid.org/0000-0002-2549-9720 
et al., 2010; Tamogami et al., 2008). MeJA is known as a typical chemical word that delivers information between plants (Arimura et al., 2010; Dar et al., 2015; Heil and Karban, 2010; McConn et al., 1997; Tamogami et al., 2008; Wu et al., 2008; Zhang and Turner, 2008).

Plants that emit chemical word upon being attacked by herbivores are referred to as emitter plants, and the ones accepting the information and responding are referred to as receiver plants (Arimura et al., 2010; Heil and Karban, 2010). Those damaged by insects are emitters, and those eavesdropping nearby are receivers. Emitter and receiver plants must be within a short distance, less than $60 \mathrm{~cm}$, from each other. They can also communicate between top and bottom of the same plant, with leaves next to them, with the same species nearby, or even with other species (Arimura et al., 2010). Moreover, communication is more effective within the same plant, and by younger plants (Radhika et al., 2008; Shiojiri and Karban, 2006). Depending on the species, some plants are good emitters and others are good receivers. The function of chemical word is developed in wild plants that are used as edible plants by humans or that take advantage of humans (Brilli et al., 2019). Genes known to affect jasmonate signal transduction in Arabidopsis thaliana are JAR1, JMT, COI1 and IHA (Arimura et al., 2005; Koo, 2018; Schilmiller and Howe, 2005; Staswick et al., 2002; Zhang and Turner, 2008).

Therefore, in this study, we examined plants that well respond to the human act of crushing plants and conducted an experiment to analyze related genes. We found that various VOCs generated in the process of crushing plants may affect plants through human breathing. In other words, we had a person actually crush plants and kill them by imitating insect attack and provided breathing air treatment to measure MeJA generated by plants.

\section{Research Methods}

\section{Generation of methyl jasmonate (MeJA) due to human behavior of crushing plants}

\section{Plant materials}

We utilized plants used by humans for edible purposes such as Lactuca sativa "Gaesebadak", Syneilesis palmata, and Peucedanum japonicum, and plants that take advantage of humans to disperse seeds such as Achyranthes japonica and Bidens bipinnata. We seeded the plants used in the experiment in a 105-cell seedling tray with water culture hydroponic sponge inserted. For the growth chamber, we used the VOC-free chamber with a circulation method that pushes the air inside toward the outside so that it is not affected by VOCs generated by humans in the cultivation process. Seedlings cultivated for 30 days on average from the date of sowing were used. The growth chamber maintained the temperature of $20-23^{\circ} \mathrm{C}$, relative humidity of approximately $60 \%$, and luminous intensity of $40 \pm 2 \mu \mathrm{mol} \cdot \mathrm{m}^{-2} \cdot \mathrm{s}^{-1}$. For watering, we filled up the watering tray with water once every three days, and top-dressed with liquid fertilizer 20 days after seeding.

\section{Formation of experimental chambers}

Experimental chambers were formed using glass, stainless and Teflon materials that do not respond to VOCs. The volume is approximately $20 \mathrm{~L}$ (width $30 \mathrm{~cm} \times$ length $30 \mathrm{~cm} \times$ height $25 \mathrm{~cm}$ ). We placed five experimental chambers in the growth chamber in which temperature, humidity and luminous intensity are regulated and maintained. After each measurement, we opened the door for ventilation to completely remove VOCs left inside and on the surface of the chambers, and wiped the walls of the chamber with distilled water using wool wipes.

\section{Treatment and measurement}

To minimize plant stress, we moved the plants from tray to glass container a day before the main measurement. In other words, we placed two individual plants each in the $150 \mathrm{~mL}$ glass container, and one glass container each per chamber. The moved plants were not to have any movement or contact for approximately 10 hours in the experimental chambers. For the control group, the experimenter's breathing air was received in a $30 \mathrm{~L}$ Tedlar bag (Top trading, Japan) before the treatment of crushing the plants. For the treatment group, the experimenter's breathing air was received in a different Tedlar bag after crushing leaves, stems and root tissues of 4-5 young individual plants for 20 minutes 
with hands. The experimenter's breathing air in the Tedlar bag is put into the chamber with plants at $15.0 \mathrm{~L} \cdot \mathrm{min}^{-1}$ (SIBATA, MP- $\Sigma 30 \mathrm{KN}$, Japan) using a pump.

MeJA in the chamber was measured using the Ion flow tube-mass spectrometry (Syft/MS, Syft voice200 Ultra, Syft Ltd, Christchurch, New Zealand) to measure real-time VOCs. The measured amount of VOCs is automatically calculated on the software (LabSyft) in the device and Standard Gas (SCOTTY ANALYZED GASES, Airgas USA) connected to the device. Analysis was performed using selected ion mode (SIM) scan. Sample scan time was set at $280 \mathrm{sec}$, and settle time at $100 \mathrm{sec}$. Ultra-pure nitrogen $\left(1.0 \mathrm{~mL} \cdot \mathrm{min}^{-1}\right)$ was used as the carrier gas. Each chamber was connected to the device using the Teflon hose, and a syringe filter (Polytetrafluoroethylene, PTFE $0.45 \mu \mathrm{m})$ is inserted in the entry of the sampling line to remove humidity and fine particulate matter that may be absorbed with the sample. Measurement began before breathing air treatment, and it was performed for 6 hours at 5-minute intervals per chamber, using the same conditions for each experiment.

\section{RNA analysis by hour after breathing air treatment of Arabidopsis thaliana}

\section{Plant materials}

Arabidopsis thaliana was seeded in the MS culture medium and used in the experiment after 23 days. Five stocks of Arabidopsis thaliana were planted in each culture bottle, and three bottles were placed in each treatment in the chamber. The incubation room conditions were maintained at the constant temperature of $25^{\circ} \mathrm{C}$, and the luminous intensity was maintained at $156 \pm 2 \mu \mathrm{mol} \cdot \mathrm{m}^{-2} \cdot \mathrm{s}^{-1}$.

\section{Treatment and plant sample collection}

Total six chambers were used. For the control group, the experimenter's breathing air was received before treatment of crushing the plant tissues and injected $1 \mathrm{~L}$ each into the three chambers. For the treatment group, the plants were crushed and killed, after which the experimenter's breathing air was received and treated $15 \mathrm{~L}$ into each chamber. Samples were collected 3 hours and 24 hours breathing air treatment. The treatment group samples were moved to the Falcon tube $(15 \mathrm{~mL})$ and quickly frozen in liquid nitrogen.

\section{RNA extraction and cDNA synthesis}

RNA was extracted from the leaves of Arabidopsis thaliana using Trizol (Invitrogen). After treating DNasel (promega) to RNA $10 \mu \mathrm{g}$ extracted, PrimeScrit RT reagent kit (TaKaRa) was used to synthesize cDNA according to the manufacturer guidelines.

\section{Real-time PCR analysis}

The synthesized cDNA is used to perform two-step qPCR, and CFX96 (Bio Rad) was used for real-time PCR. For amplification response, $10 \mu 12 \mathrm{x}$ SYBR Premix Ex Taq(SRbiolab), $2 \mathrm{uL}$ primer (finally $500 \mathrm{nM}$ ), and $2 \mathrm{uL}$ cDNA are mixed into total amount of $20 \mu 1$ and responded for 10 seconds at $95^{\circ} \mathrm{C}$ in the beginning. The 5 -second cycle was performed 45 times at $95^{\circ} \mathrm{C}$ and the 30 -second cycle at $60^{\circ} \mathrm{C}$, conducting qPCR by repeating the process three times per sample. $2^{\wedge}-\Delta \Delta \mathrm{Ct}$ method(Livak and Schmittgen, 2001) was used to analyze relative normalized expression of each line.

\section{Results and Discussion}

\section{Generation of methyl jasmonate (MeJA) due to human behavior of crushing plants}

We compared the amount of MeJA generated in wild plants used by humans for edible purposes (Syneilesis palmata, Peucedanum japonicum) and wild plants that take advantage of humans to disperse seeds (Achyranthes japonica, Bidens bipinnata) (Fig. 1). Plants used by humans for edible purposes such as Peucedanum japonicum and Syneilesis palmata had 0.3518 and 0.3575 ppb of MeJA generated each, showing little difference. Moreover, plants that take advantage of humans to disperse seeds such as Achyranthes japonica and Bidens bipinnata had 0.0405 and $0.0398 \mathrm{ppb}$ of MeJA generated each, showing almost no difference.

MeJA is known to be a typical aroma substance among 


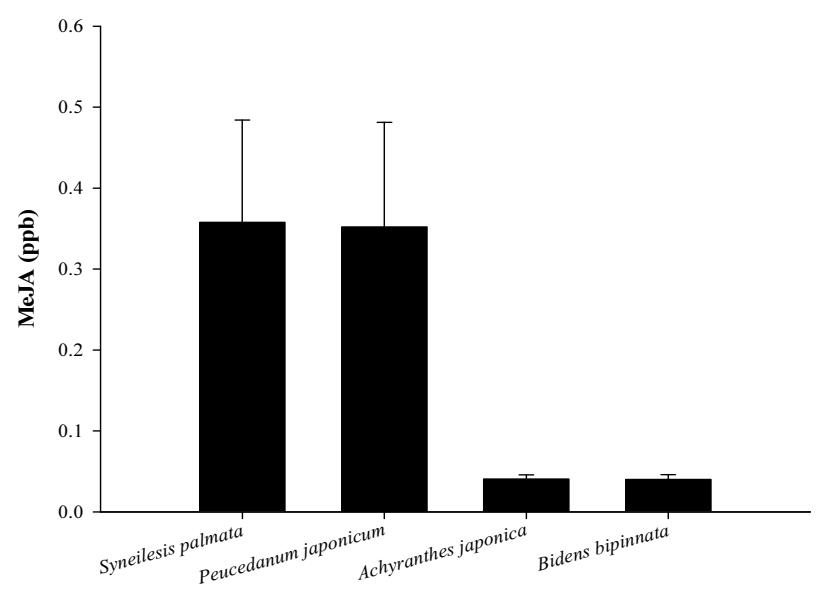

Fig. 1. Methyl jasmonate (MeJA) prduction from four wild plants. People use Syneilesis palmata and Peucedanum japonicum for edible purposes while Achyranthes japonica and Bidens bipinnata use human for seed dispersal. Plants were placed in the $20 \mathrm{~L}$ chamber and exposed to human breaths for 6 hrs. Error bars represent the SE.

chemical words that alert not only oneself but also other plants to generate defensive secretion when damaged by herbivores (Arimura et al., 2010; Heil and Karban, 2010). This amount of MeJA generated used as chemical word was higher in the wild plants used by humans for edible purposes (Syneilesis palmata, Peucedanum japonicum) than the wild plants taking advantage of humans (Achyranthes japonica, Bidens bipinnata). In general, species growing in wildlife are known to more sensitively respond to chemical words than species developed by humans, and thus this study used wild vegetable species not developed by humans.

According to Karban et al. (2000), when clipped sagebrush (Artemisia tridentata) is damaged, it generated 10.8 times more MeJA than the control group without damage, and its surrounding plants generate a great amount of antioxidant enzymes and polyphenol oxidase, thus avoiding attack from herbivores.

We monitored the amount of MeJA generated in the three species of plants used by humans for edible purposes by hour (Fig. 2). On average, the amount of MeJA generated was from $0.2 \mathrm{ppb}$ to $0.4 \mathrm{ppb}$. The concentration fluctuated and showed consistent values without much change, but overall it slightly increased over time.

We compared the control group with human breathing air treatment into the chamber containing Peucedanum japonicum and the treatment group with breathing air re-

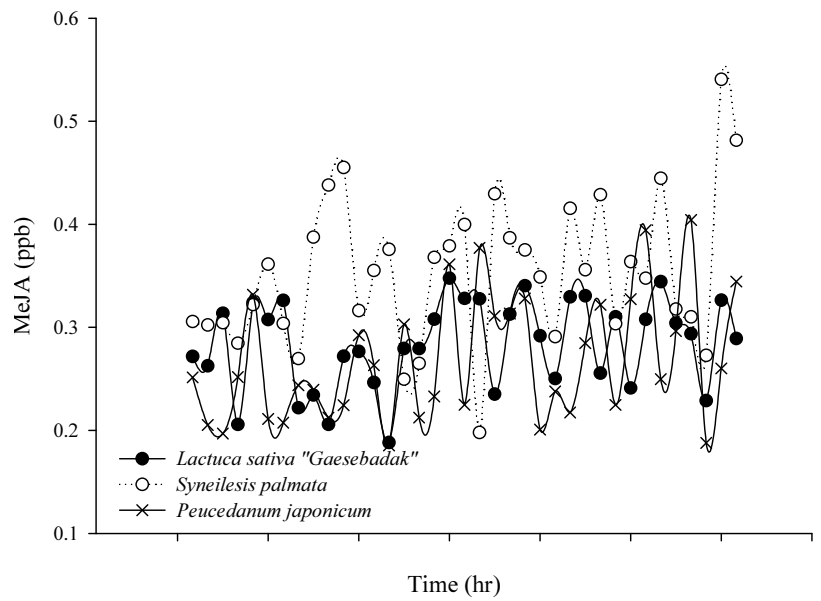

Fig. 2. Changes of methyl jasmonate (MeJA) concentrations in three edible plants. Plants were placed in the $20 \mathrm{~L}$ chamber without getting exposed to human breaths.

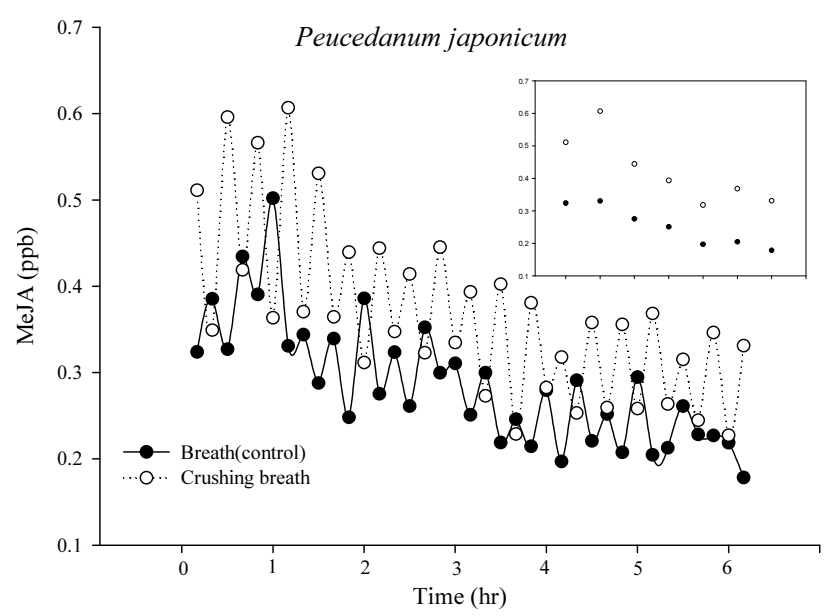

Fig. 3. Changes of methyl jasmonate (MeJA) concentrations in Peucedanum japonicum. Plants were placed in the $20 \mathrm{~L}$ chamber, wounded by crushing for $20 \mathrm{~min}$, and exposed to human breaths (open circle). Control plants was exposed to human breaths without getting wounded (closed circle). Nested box shows MeJA concentrations every hour.

ceived after crushing Peucedanum japonicum (Fig. 3). Small figure only indicated values of MeJA every hour. In both the control group and treatment group, MeJA concentration increased and then decreased again in 1 hour, but the treatment group showed higher concentration than the control group. The initial concentration was 0.32 and $0.51 \mathrm{ppb}$ in the control group and treatment group, but after 1 hour it increased to 0.33 and $0.61 \mathrm{ppb}$. Thus, concentration increased by $0.01 \mathrm{ppb}$ in the control group after 1 hour, but by $0.1 \mathrm{ppb}$ in the treatment group, and the 


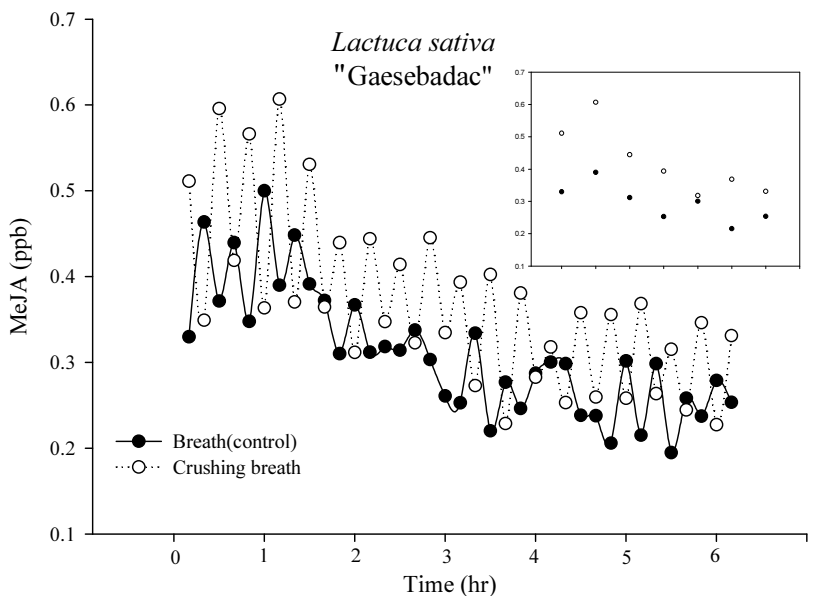

Fig. 4. Changes of methyl jasmonate (MeJA) concentrations in Lactuca sativa. Plants were placed in the $20 \mathrm{~L}$ chamber, wounded by crushing for 20 min, and exposed to human breaths (open circle). Control plants was exposed to human breaths without getting wounded (closed circle). Nested box shows MeJA concentrations every hour.

difference between the two was approximately $0.28 \mathrm{ppb}$. After 6 hours, the amount was 0.18 and 0.33 ppb in the control group and treatment group, showing a decrease of 0.14 and $0.18 \mathrm{ppb}$ compared to the initial concentration.

The initial MeJA concentration of Lactuca sativa "Gaesebadak" was 0.33 and $0.51 \mathrm{ppb}$ in the control group and treatment group, but after 1 hour it increased to 0.39 and $0.61 \mathrm{ppb}$ (Fig. 4). Thus, concentration increased by $0.06 \mathrm{ppb}$ in the control group, but by $0.1 \mathrm{ppb}$ in the treatment group. The difference between the two after 1 hour was approximately $0.22 \mathrm{ppb}$. After 6 hours, the amount was 0.25 and $0.33 \mathrm{ppb}$ in the control group and treatment group.

The initial MeJA concentration of Syneilesis palmata was 0.30 and $0.34 \mathrm{ppb}$ in the control group and treatment group, but after 1 hour it increased to 0.32 and $0.37 \mathrm{ppb}$ (Fig. 5). Thus, concentration increased by $0.02 \mathrm{ppb}$ in the control group and by $0.05 \mathrm{ppb}$ in the treatment group. The difference between the two after 1 hour was approximately $0.03 \mathrm{ppb}$, which was very small. After 6 hours, the amount was 0.21 and $0.0 .28 \mathrm{ppb}$ in the control group and treatment group.

When attacked by herbivores such as insects, plants generate defensive secretion and alert this to other plants (Arimura et al., 2010; Heil and Karban, 2010; Holopainen and Gershenzon, 2010; Kaplan, 2012; von Mérey et al.,

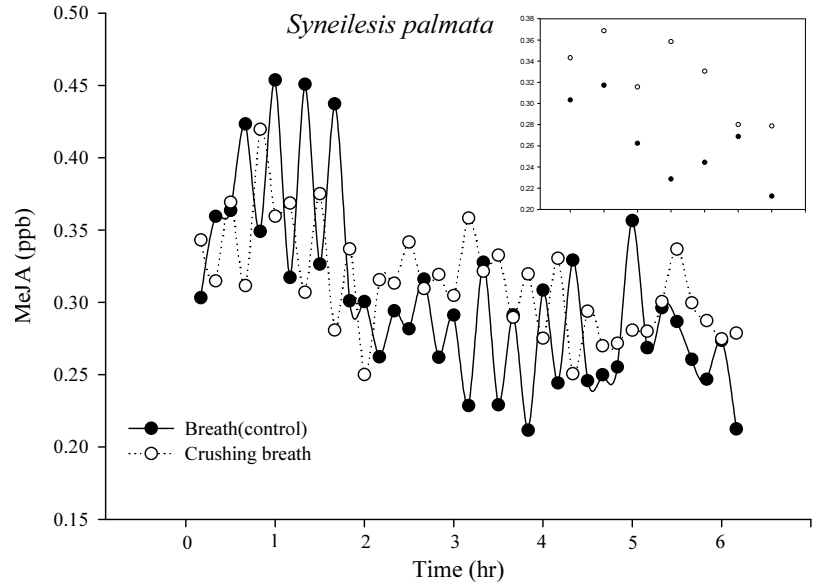

Fig. 5. Changes of methyl jasmonate (MeJA) concentrations in Syneilesis palmata. Plants were placed in the $20 \mathrm{~L}$ chamber, wounded by crushing for $20 \mathrm{~min}$, and exposed to human breaths (open circle). Control plants was exposed to human breaths without getting wounded (closed circle). Nested box shows MeJA concentrations every hour.

2011). For wild edible plants in the mountains attacked by herbivores, humans may perform the same role as injurious insects. Thus, human breathing air was used to prove that plants respond to human attack as they do to insect attack. One species of plant is crushed and killed, after which the experimenter's breathing air received was treated to other individuals in the same species. It is assumed that various substances that are generated by plants when killing them may remain in the body through human breathing and then delivered to plants again through breathing air. Syft/MS that measures aroma substance MeJA generated by plants on a real-time basis was used to prove the assumption. Moreover, chambers were formed so that no relationship between plants and humans is built with odor substance while raising the plants. As a result, just human breathing air caused plants to generate MeJA, but the amount generated increased in breathing air after crushing them. Plants seemed to have responded to human attack and increased the amount of MeJA they generate, which is a chemical word that alerts other plants.

\section{RNA analysis by hour after breathing air treatment of Arabidopsis thaliana}

JAR1 and JMT genes of Arabidopsis thaliana according to breathing air treatment time received after crushing the 


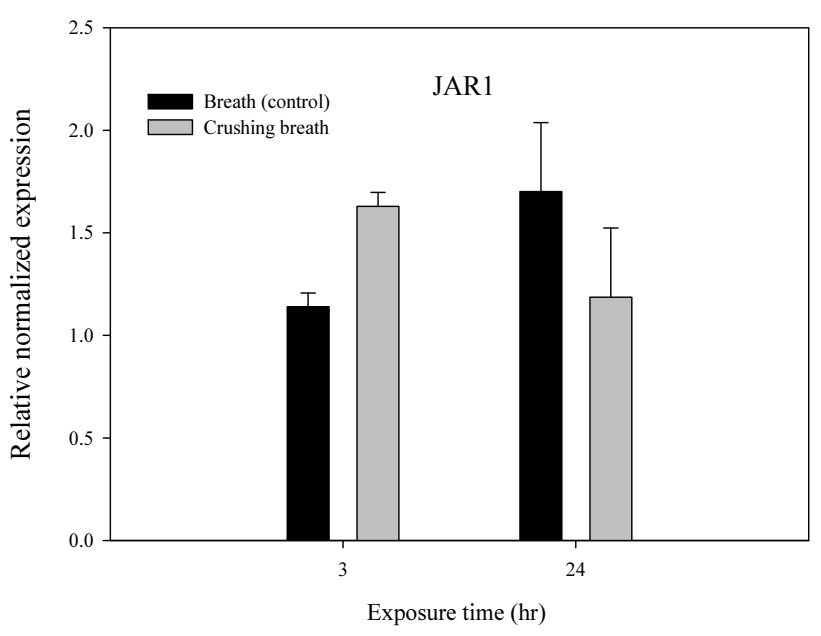

Fig. 6. Relative normalized expression of Jasmonate Resistant 1 (JAR1) in Arabidopsis thaliana. Plants were placed in the 20L chamber, wounded by crushing (not wounded for control), and exposed to human breaths for 3 or $24 \mathrm{hr}$. Error bars represent the SE.

plants showed an increase in relative normalized expression after 3 hours compared to the control group, thereby showing increased activity (Figs. 6 and 7). However, all of JAR1, JMT, IAH, and COI showed a decrease in relative normalized expression after 24 hours, showing decreased activity (Figs. 6, 7, 8 and 9).

JAR1 gene showed the relative normalized expression of 1.14 in the control group and 1.63 in the treatment group after 3 hours, showing that it was 0.49 higher in the treatment group (Fig. 6). However, the relative normalized expression was 1.70 and 1.19 after 24 hours, showing that it was 0.51 lower in the treatment group. Moreover, JMT gene showed the relative normalized expression of 1.23 in the control group and 3.27 in the treatment group after 3 hours, showing that it was 2.04 higher in the treatment group (Fig. 7). However, the relative normalized expression was 5.50 and 4.27 after 24 hours, showing that it was 1.23 lower in the treatment group.

IAH gene showed the relative normalized expression of 1.81 in the control group and 1.92 in the treatment group after 3 hours, showing little difference between the two (Fig. 8). However, the relative normalized expression was 2.09 and 0.86 after 24 hours, showing that it was 1.23 lower in the treatment group. COI1 gene showed the relative normalized expression of 1.93 in the control group and 1.20 in the treatment group after 3 hours, which was

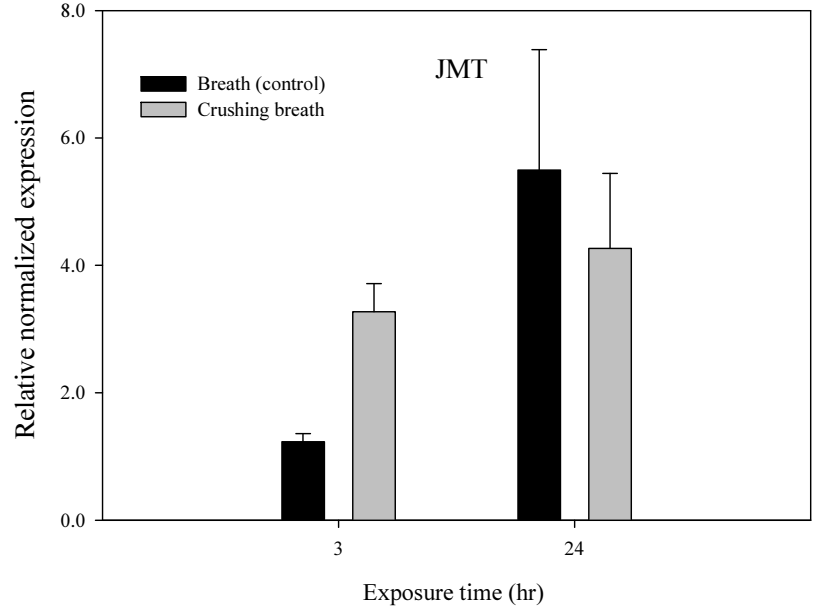

Fig. 7. Relative normalized expression of JA Carboxyl Methyl Transferase (JMT) in Arabidopsis thaliana. Plants were placed in the $20 \mathrm{~L}$ chamber, wounded by crushing (not wounded for control), and exposed to human breaths for 3 or $24 \mathrm{hr}$. Error bars represent the SE.

0.73 higher in the control group (Fig. 9). Moreover, even after 24 hours, the relative normalized expression was 3.12 and 2.12 and thus 1.00 higher in the control group. In other words, both groups showed a slight increase in relative normalized expression over time.

We intended to not only measure the amount of MeJA generated, which is a chemical word, using Syft/MS, but also analyze the genes involved in MeJA generation and increase reliability of the measures. MeJA generation mostly involves four genes: JAR1, COI1, IAH, and JMT (Koo, 2018; Staswick et al., 2002). As a result of analyzing these four genes, it was found that JAR1 and JMT best responded to human breathing air (Figs. 6, 7, 8, and 9). Response to human breathing air before and after crushing the plants increased significantly in JAR1 and JMT after 3 hours. However, it rather decreased after 24 hours. The amount of MeJA generated measured real-time was highest 1 hour after breathing air treatment (Figs. 2, 3, and 4).

As a result, real-time amount of MeJA generated and related genes such as JAR1 and JMT showed the same tendency of increase due to breathing air treatment after crushing the plants (Figs. 3, 4, 5, 6, 7, 8, and 9). Further research is needed on response to plant MeJA generation over time after human breathing air treatment. 


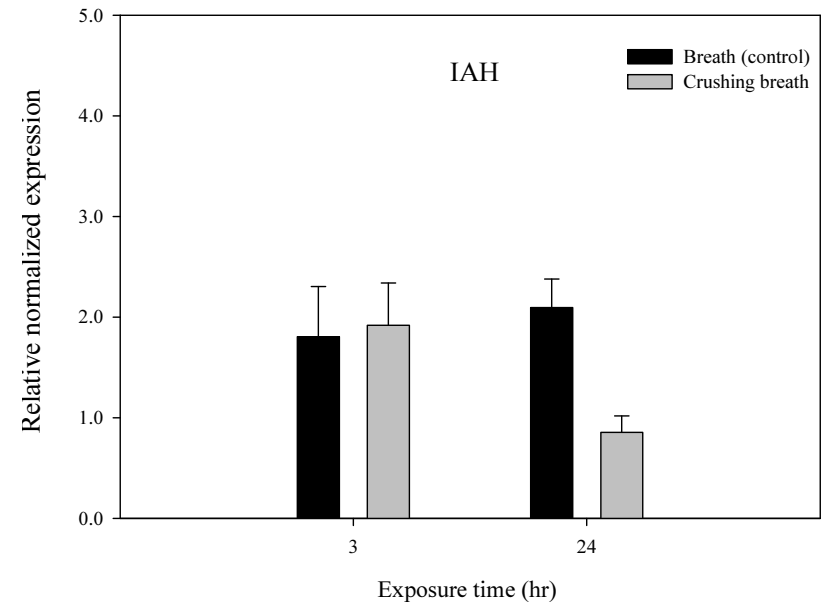

Fig. 8. Relative normalized expression of ILR1-like Aminohydrolase $(\mathrm{IAH})$ in Arabidopsis thaliana. Plants were placed in the 20L chamber, wounded by crushing (not wounded for control), and exposed to human breaths for 3 or $24 \mathrm{hr}$. Error bars represent the SE.

\section{Conclusion}

This study was conducted to determine whether plants respond to human behavior. We intended to determine whether the human act of killing plants affects other plants in the same species. For the act of killing plants, leaves, stems and root tissues of young plants were crushed with hands for 20 minutes. It was assumed that various VOCs would be generated from the plants as they feel the threat of death in the process of having their plant tissues crushed, which would affect other plants through human breathing. To prove this assumption, MeJA known as a chemical word was measured on a real-time basis. Moreover, to increase reliability of the measures, genes involved in MeJA generation were analyzed. The results showed that Peucedanum japonicum responded most to human behavior. The amount of MeJA generated was biggest after about 1 hour due to the breathing air received before or after crushing the plants, but it was bigger after crushing the plants. Genes involved in MeJA generation were also analyzed, and the results showed that the genes showing the same tendency as the amount of MeJA generated (greater than the control group) were JAR1 and JMT in the real-time Syft/Mass Spectrometer analysis after crushing the plants. In other words, JAR1 and JMT genes showed higher relative normalized expression in the treatment group than the control

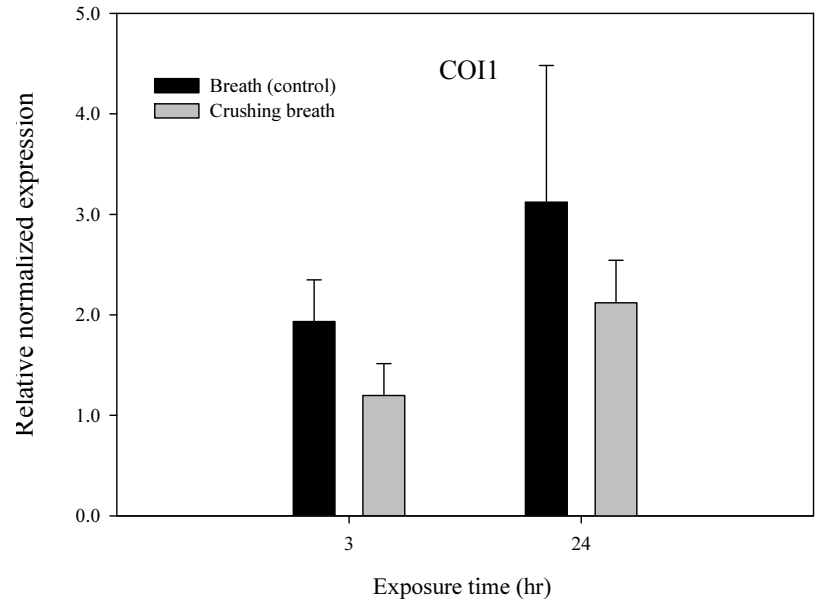

Fig. 9. Relative normalized expression of Coronatine Insensitive 1 (COI1) in Arabidopsis thaliana. Plants were placed in the 20L chamber, wounded by crushing (not wounded for control), and exposed to human breaths for 3 or $24 \mathrm{hr}$. Error bars represent the SE.

group after 3 hours. However, it is necessary to investigate more specific gene responses by hour. This experiment has significance as the first research to determine partial correlation in communication between humans and plants, but many tasks still remain for further research.

\section{References}

Arimura, G., C. Kost, and W. Boland. 2005. Herbivore-induced, indirect plant defences. Biochim. Biophys. Acta 1734(2):91-111. https://doi.org/10.1016/j.bbalip.2005.03.001

Arimura, G., K. Shiojiri, and R. Karban. 2010. Acquired immunity to herbivory and allelopathy caused by airborne plant emissions. Phytochemistry 71(14-15):1642-1649. https://doi.org/10.1016/j.phytochem.2010.06.021

Brilli, F., F. Loreto, and I. Baccelli. 2019. Exploiting plant volatile organic compounds (VOCs) in agriculture to improve sustainable defense strategies and productivity of crops. Front. Plant Sci. 10:264. https://doi.org/10.338 9/fpls.2019.00264

Dar, T.A., M. Uddin, M.M.A. Khan, K.R. Hakeem, and H. Jaleel. 2015. Jasmonates counter plant stress: A review. Environ. Exp. Bot. 115:49-57. https://doi.org/10.1016/j. envexpbot.2015.02.010

Engelberth, J., H.T. Alborn, E.A. Schmelz, and J.H. 
Tumlinson. 2004. Airborne signals prime plants against insect herbivore attack. Proc. Natl. Acad. Sci. 101(6): 1781-1785. https://doi.org/10.1073/pnas.0308037100

Heil, M. and R. Karban. 2010. Explaining evolution of plant communication by airborne signals. Trends Ecol. Evol. 25(3):137-144. https://doi.org/10.1016/j.tree.2009.09.010.

Holopainen, J.K. and J. Gershenzon. 2010. Multiple stress factors and the emission of plant VOCs. Trends Plant Sci. 15(3):176-184. https://doi.org/10.1016/j.tplants.201 0.01 .006

Kaplan, I. 2012. Attracting carnivorous arthropods with plant volatiles: The future of biocontrol or playing with fire? Biol. Control 60(2):77-89. https://doi.org/10.1016/ j.biocontrol.2011.10.017

Karban, R., I.T. Baldwin, K.J. Baxter, G. Laue, and G.W. Felton. 2000. Communication between plants: Induced resistance in wild tobacco plants following clipping of neighboring sagebrush. Oecologia 125(1):66-71. https://doi.org/10.1007/PL00008892

Koo, A.J. 2018. Metabolism of the plant hormone jasmonate: A sentinel for tissue damage and master regulator of stress response. Phytochem. Rev. 17(1):51-80. https://doi.org/10.1007/s11101-017-9510-8

Livak, K.J. and T.D. Schmittgen. 2001. Analysis of relative gene expression data using real-time quantitative PCR and the 2- $-\Delta \mathrm{CT}$ method. Methods 25(4):402-408.

Loreto, F. and J.P. Schnitzler. 2010. Abiotic stresses and induced BVOCs. Trends Plant Sci. 15(3):154-166. https://doi.org/10.1016/j.tplants.2009.12.006

McConn, M., R.A. Creelman, E. Bell, J.E. Mullet, and J. Browse. 1997. Jasmonate is essential for insect defense in Arabidopsis. Proc. Natl. Acad. Sci. USA 94(10): 5473-5477. https://doi.org/10.1073/pnas.94.10.5473

Radhika, V., C. Kost, S. Bartram, M. Heil, and W. Boland. 2008. Testing the optimal defence hypothesis for two indirect defences: extrafloral nectar and volatile organic compounds. Planta 228(3):449-457. https://doi.org/10.1 007/s00425-008-0749-6
Schilmiller, A.L. and G.A. Howe. 2005. Systemic signaling in the wound response. Curr. Opin. Plant Biol. 8(4):369-377. https://doi.org/10.1016/j.pbi.2005.05.008

Shiojiri, K. and R. Karban. 2006. Plant age, communication, and resistance to herbivores: young sagebrush plants are better emitters and receivers. Oecologia 149(2):214-220. https://doi.org/10.1007/s00442-006-0441-0

Staswick, P.E., I. Tiryaki, and M.L. Rowe. 2002. Jasmonate response locus JAR1 and several related Arabidopsis genes encode enzymes of the firefly luciferase superfamily that show activity on jasmonic, salicylic, and indole-3-acetic acid in an assay for adenylation. Plant cell 14(6):1405-1415. https://doi.org/10.1105/tpc.000885

Tamogami, S., R. Rakwal, and G.K. Agrawal. 2008. Interplant communication: Airborne methyl jasmonate is essentially converted into JA and JA-Ile activating jasmonate signaling pathway and VOCs emission. Biochem. Biophys. Res. Commun. 376(4):723-727. https://doi.org/10.1016/ j.bbrc.2008.09.069

von Mérey, G., N. Veyrat, G. Mahuku, R.L. Valdez, T.C.J. Turlings, and M. D'Alessandro. 2011. Dispensing synthetic green leaf volatiles in maize fields increases the release of sesquiterpenes by the plants, but has little effect on the attraction of pest and beneficial insects. Phytochemistry 72(14-15):1838-1847. https://doi.org/10.1016/j.phytoche m.2011.04.022

Wu, J., L. Wang, and I.T. Baldwin. 2008. Methyl jasmonate-elicited herbivore resistance: does MeJA function as a signal without being hydrolyzed to JA? Planta 227(5): 1161-1168. https://doi.org/10.1007/s00425-008-0690-8

Zhang, Y. and J.G. Turner. 2008. Wound-induced endogenous jasmonates stunt plant growth by inhibiting mitosis. PLos One 3(11):e3699. https://doi.org/10.1371/journal.pone.0 003699

Zuo, Z.J., Y.R. Zhu, Y.L. Bai, and Y. Wang. 2012. Volatile communication between Chlamydomonas reinhardtii cells under salt stress. Biochem. Syst. Ecol. 40:19-24. https://doi.org/10.1016/j.bse.2011.09.007 